\title{
Reducing Characteristics of Metal Diisobutyl-t-butoxyaluminum Hydrides for Tertiary Amides
}

\author{
Seong Jib Choi, Kang Jin Lee, Gwi Bin Lee, and Duk Keun An \\ Deparment of Chemistry and Institute for Holecular Science and Fusion Technologv, Kangwon Kational Lhiversity, \\ Chunchon 200-701, Korea. "E-mail: akan akangwon.ackr \\ Received Mav 13, 2008
}

Key Words : Metal diisobutyl-t-butoxyahuminum hỵdride. Aldehyde. Tertiary amide. Partial reduction

A simple and useful partial reduction of tertiary anides into aldehydes is one of the highly desirable means in organic synthesis, and hence some useful reducing agents for this have been reported. ${ }^{1}$ Recently, we have reported that a new class of reducing agents. metal diisobutyl-t-butoxyaluninum hydrides such as lithium dissobutyl-t-butoxyaluminum hydride (LDBBA), sa sodium dissobutyl-t-butoxyaluminum hydride (SDBBA) ${ }^{\text {sb }}$ and potassium diisobutyl-tbutoxyaluninum hydride (PDBBA) ${ }^{\text {ic }}$ are new effective partial reducing agents which can reduce various esters to aldehydes in high yields. Among them, LDBBA was especially effective for partial reduction of isopropyl esters to aldehydes usually in higher than $90 \%$ at $0{ }^{\circ} \mathrm{C}$. Also. SDBBA and PDBBA were effective for partial reduction of conumon methyl and ethyl esters in high yield $(71-93 \%)$ at 0 ${ }^{\circ} \mathrm{C}$.

With these results in hand. we anticipated that metal dissobuyl-t-butoxyaluminum hydrides (LDBBA, SDBBA and PDBBA) would also be effective in developing an efficient method for partial reduction of tertiary anides. Herein, we wish to report the results of our study for partial reduction of tertiary amides to aldehydes (Scheme 1)

\section{Results and Discussion}

The common metal (Li. $\mathrm{Na}$. K) disobutyl-t-butoxyaluminum hydrides can be readily prepared by a simple reaction of $\mathrm{DIBAH}$ with the corresponding metal $t$-butoxides in THF at $0^{\circ} \mathrm{C}$ or room temperature.

We first examined the partial reduction of $N, N$-diniethylbenzanide as a representative with $\angle D B B A, S D B B A$. and PDBBA in THF at room temperature to find ou an optimum reaction conditions. The results are summarized in Table 1.

As shown in Table 1, the LDBBA was more readily reduced the $N, N$-dimetlylbenzanide to benzaldehyde than

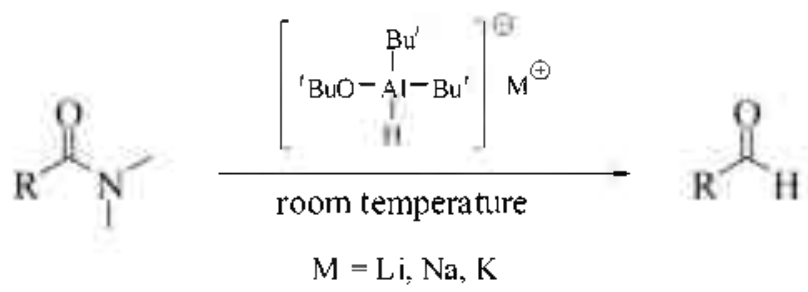

Scheme 1
Table 1. Reduction of $\mathrm{N} N$-dimethylbenzamide with metal diisobutyl-t-butoxyaluminum hydrides at room temperature

\begin{tabular}{|c|c|c|c|c|}
\hline \multirow{2}{*}{ Compound } & \multirow{2}{*}{ Hydride } & \multicolumn{2}{|c|}{ Reaction Londition } & \multirow{2}{*}{$\begin{array}{c}\text { Yield of } \\
\text { aldehyde }(\%)\end{array}$} \\
\hline & & $\mathrm{H}^{-}$ & time (h) & \\
\hline \multirow{16}{*}{$\begin{array}{c}\text { N.S-dimethyl- } \\
\text { benzamide }\end{array}$} & \multirow[t]{5}{*}{ LDBBA } & 1.2 & 3 & 52 \\
\hline & & & 12 & 89 \\
\hline & & & 24 & 58 \\
\hline & & 1.5 & l & 82 \\
\hline & & & 3 & 84 \\
\hline & \multirow[t]{9}{*}{ SDBBA } & 1.2 & 24 & 65 \\
\hline & & 1.3 & 24 & 72 \\
\hline & & 1.5 & 3 & 42 \\
\hline & & & 6 & 61 \\
\hline & & & 12 & 70 \\
\hline & & & 24 & 90 \\
\hline & & 2.0 & l & 33 \\
\hline & & & 3 & 52 \\
\hline & & & 6 & 70 \\
\hline & \multirow[t]{2}{*}{ PDBBA } & 1.5 & 5 & trace \\
\hline & & 1.5 & 24 & trace \\
\hline
\end{tabular}

${ }^{a}$ Yields were determined by GC.

SDBBA at room temperature. Especially, the PDBBA almost did not reacted with $N, N$-dimetlyylbenzanide under the similar condition. The reactivity may be attributed to the electronic effect of the counter metal cations in the metal dissobutyl-t-butosyaluminum lydrides. Using the best reaction condition from the experimental results. we applied these reducing agents for the synthesis of aldelydes from the various tertiary anides, respectively. The results for representative tertiary amides are summarized in Table 2.

As shown in Table 2, both LDBBA and SDBBA were good to convert tertiary amides to the corresponding aldehydes. Thus, various aromatic amides examined possessing electron-withdrawing or electron-donating groups are readily converted to the corresponding aldelydes. A simple aliphatic and heterocyclic amide is also readily reduced to aldehydes in high yields.

The utility of metal dissobutyl-i-butoxyaluminum hydrides (LDBBA. SDBBA and PDBBA) as a partial reducing agent for tertiary amides to aldelyydes has been examined in this study. Among them. both LDBBA and SDBBA appeared to be an excellent reagent for partial reduction of tertiary 
Table 2. Yields of aldelnydes in the partial reduction of representative tertiary amides with LDBBA, SDBBA and PDBBA at room temperature

\begin{tabular}{|c|c|c|c|c|}
\hline \multirow{2}{*}{ Entry } & \multirow{2}{*}{ Compound } & \multicolumn{3}{|c|}{ Yield of aldehyde $(\%)^{a}$} \\
\hline & & LDBBA $^{2 t}$ & $\mathrm{SDBBA}^{\mathrm{C}}$ & $\mathrm{PDBBA}^{c}$ \\
\hline 1 & N, v-dimethyllbenzamide & 89 & 90 & trace \\
\hline 2 & $\mathrm{~N}, \mathrm{~V}$-dimethyl-4-chlorobenzamide & 93 & 88 & trace \\
\hline 3 & N,N-dimethyl-4-chlorobenzamide & 92 & 89 & trace \\
\hline 4 & N,N-dimethyl-3-chlorobenzamide & 85 & 74 & trace \\
\hline 5 & N, N-dimethyl-3-toluamide & 88 & 84 & trace \\
\hline 6 & N, N-dimethyl-4-methoxybenzamide & 90 & 79 & trace \\
\hline 7 & N, N-dimethy]-4-naphthylamide & 90 & 91 & trace \\
\hline 8 & $\mathrm{~N}, \mathrm{~V}$-dimethyl-4-furoamide & 82 & 74 & trace \\
\hline 9 & N, N-dimethylcaproamide & $87^{i}$ & $81^{\circ}$ & trace \\
\hline
\end{tabular}

"Yields were detennined by GC. "Reacted for $12 \mathrm{~h}$. reagent:compound $=1.2: 1$. "Reacted for $24 \mathrm{~h}$. reagent:compound $=1.5: 1$. "Reacted for $24 \mathrm{~h}$. reagent:compound $=1,2: 1 .{ }^{\circ}$ Reacted for $24 \mathrm{~h}$. reagent:compound $=3: 1$.

anides under the mild condition. Therefore. these reagents are should be useful as a reagent of choice for the synthesis of aldeliydes from tertiary amides.

\section{Experimental Section}

General. All glassware used was dried thoroughly in an oven, assembled hot. and cooled under a strean of dry nitrogen prior to use. All reaction and manipulation of air and moisture sensitive materials were carried out using standard techniques for handling air sensitive materials. All chemicals except tertiary anides were commercial products of the highest pure which were purified further by standard methods before use. THF was dried over sodium-benzophenone and distilled. Diisobutylaluminum hydride (DIBAH), nbutyllithium, $t$-butyl alcohol. sodium $t$-butoxide and potassiun $t$-butoxide were purchased from Aldrich Chemical Company. Tertiary amides were prepared by the method of Brown and Tsukanoto. ${ }^{\text {te }} \mathrm{GC}$ analyses were performed on a Donam DS 6200 FID chromatograph. using a HP-1 capillary column ( $30 \mathrm{~m}$ ). All GC yields were determined with use of a suitable internal standard and authentic mixture. The concentration of metal diisobutyl-t-butoxyaluminum hydrides solution in THF-hexane was measured gasometrically by hydrolysis of an aliquot of the solution with a hydrolyzing mixture of $t$-butyl alcohol-THF $(1: 1)$ at $0^{\circ} \mathrm{C}$.

Preparation of LDBBA. To a solution of $t$-butyl alcohol $(5.16 \mathrm{~mL}, 55 \mathrm{mmol})$ in THF $(25 \mathrm{~mL})$ was added $n$-butyllithium $\left(20 \mathrm{~mL}, 2.5 \mathrm{M}\right.$ in hexane. $55 \mathrm{mmol}$ ) at $0^{\circ} \mathrm{C}$. After being stirred for $\mathrm{l} h$ at room temperature. DIBALH $(50 \mathrm{~mL}$. $1.0 \mathrm{M}$ in hexane. $50 \mathrm{mmol}$ ) was added dropwise to the reaction mixture at $0^{\circ} \mathrm{C}$ and the mixture was stirred for $2 \mathrm{~h}$ at room temperature to give a colorless homogeneous solution.

Preparation of SDBBA and PDBBA. To a solution of sodium $t$-butoxide $(5.05 \mathrm{~g}$. $52.5 \mathrm{mmol})$ or potassium $t$ - butoxide (5.89 g. $52.5 \mathrm{mmol}$ ) in THF ( $50 \mathrm{~mL}$ ). DIBALH (50 $\mathrm{mL}, 1.0 \mathrm{M}$ in hexane. $50 \mathrm{mmol}$ ) was added dropwise at $0^{\circ} \mathrm{C}$ and the mixture was stirred for $2 \mathrm{~h}$ at room temperature to give a colorless homogeneous solution.

Stability of new hydlides. The LDBBA, SDBBA and PDBBA solutions were stable in the refrigerator for 6 months without any appreciable loss of hydride content.

Reduction of tertiary amides to aldehydes. The following procedure for the reduction of $N, N$-dimetlyylbenzamide with LDBBA is representative. To a solution of $N, N$-dimethylbenzanide $(0.075 \mathrm{~g} .0 .5 \mathrm{mmol})$ in THF $(5 \mathrm{~mL})$ containing naphthalene as an internal standard was added LDBBA (1.3 mL. 0.46 M in THF-hexane) at room temperature. After $12 \mathrm{~h}$, the reaction mixture was hydrolyzed with $5 \mathrm{~mL}$ of $1 \mathrm{~N} \mathrm{HCl}(a q)$ and the product was extracted with 10 $\mathrm{mL}$ of diethyl ether. The ether layer was dried over anhydrous magnesium sulfate. GC analy sis showed an $89 \%$ yield of benzaldehyde.

\section{References}

1. (a) Lithium aluminium hydride: Hudlicky. M. Reductions in Organic Chenistry: Ellis Horwood Limited: Chichester. England. 1984. (b) Sodium alumininohydrate: Zakharkin. L. I.: Maslin. D. N.: Gavrilenko, V. V. Tetrahedron 1969, 25, 5555. (c) Lithium dior triethoxyaluminohydride: Brown, H. C, Tsukamoto, T. $J$. Am. Chent Soc. 1964. 86. 1089. (d) Aminoaluminum hydride: Muraki. M.: Mukaiyama. I. Chent. Lett. 1975. 875. (e) Sodium diethyldihydroaluminate (SDDA): Yoon. N. M.: Gyoung. Y. S. Bull. Korean Chem. Soc. 1992. 13, 341. (f) Dissobutylaluminum hydride: Zalharkin. L. I.: Khorlina, I. M. Dokl. Akad Nauk SSSR 1959. 2146. (g) Lithium disobutylpiperidinohydroaluminate: Woo. S. M.: Kim. M. E.: Ant. D. K. Bill. Konean Chem. Soc. 2006. 27. 121.

2. (a) Kiml. M. S.: Choi. Y. M.: An. D. K. Tetrahedron Lett. 2007.48. 5061. (b) Song. J. I: An, D. K. Chem. Lett. 2007. 36. 886. (c) Chae. M. J: Song. J. I: An. D. K. Bull. Kowan Chem. Soc. 2007. 28.2517. 